\title{
Pharmacological Characterization and Raman Spectroscopy Evaluation of Oral and Maxillofacial Surgery-Related Carnoy'S Solution Modified by Different Viscosity Agents
}

\author{
Francisco Samuel Rodrigues Carvalho ${ }^{*}$, Marina Mota Lima Verde ${ }^{2}$, Khalil \\ Fernandes Viana ${ }^{3}$, Thâmara Manoela Marinho Bezerra ${ }^{4}$, Said Gonçalves da \\ Cruz Fonseca ${ }^{5}$, Karuza Maria Alves Pereira ${ }^{6}$, Thyciana Rodrigues Ribeiro ${ }^{7}$, \\ Fábio Wildson Gurgel Costa ${ }^{8}$
}

\begin{abstract}
Background: There are several lesions of odontogenic and non-odontogenic origin in the oral cavity, such as odontogenic keratocyst, as well as many treatment options for such lesions. In order to reduce recurrence due to conservative treatments and less aesthetic and functional impairment of the patient (radical therapies), Carnoy's solution has been used as an adjuvant to surgery, showing satisfactory results. Its application is not standardized, presenting risks to adjacent tissues. Thus, we characterized the Carnoy's solution with different viscosity agents to enhance its applicability. Material and Methods: All solutions prepared (Carnoy with and without chloroform) were added with viscosity agent: ethyl cellulose, propylene glycol, and glycerol totaling eight solutions. The pharmacological characterization of the solutions was performed by determining the mass density and relative density (using a clean and dry pycnometer), $\mathrm{pH}$ (using $\mathrm{pH}$ meter), and concentration of $\mathrm{Fe}^{3+}$ (using ultraviolet/visible spectroscopy). The analyses of the inorganic components were determined by Raman micro spectrometry. Data were analyzed with statistical program BIOESTAT 5.3. Results: Solutions with ethyl cellulose were discarded due to precipitate formation and suspension of the viscosity agent. In the other solutions, viscosity increase (propylene glycol solutions) and acidic pH were observed mainly in the glycerol group. The ferric chloride characterized as a hemostatic agent had its concentration increased with the use of thickening agents, theoretically favoring its action. Conclusion: The similarity of the propylene glycol and glycerol molecules justifies the Raman spectra of these substances to be similar and the difficulty in obtaining a "fingerprint".
\end{abstract}

Keywords: Carnoy's solution- oral surgery- Raman Spectroscopy

Asian Pac J Cancer Prev, 20 (11), 3335-3339

\section{Introduction}

The dental surgeon may find in his clinical practice several lesions, odontogenic and non-odontogenic, affecting the maxillofacial complex (Cavalcante et al., 2016; da Silva et al., 2018). Some of these lesions are not necessarily associated with painful symptoms and are diagnosed on routine imaging tests (Alves et al., 2018). Among these lesions we can highlight odontogenic keratocyst (OKT) and amelobastoma, which, despite being a benign pathology, is locally invasive and associated with high rates of relapse. Conservative treatment may be associated with recurrence, while radical surgery may result in aesthetic-functional impairment (Alves et al., 2018).
Several modalities of therapy complementary to surgery have been widely used, among them cryotherapy and the use of the Carnoy's solution (Stoelinga, 2001; Stoelinga and Bronkhorst, 1988; Voorsmit, 1985; Voorsmit et al., 1981). A systematic review with a meta-analysis of 2.287 odontogenic tumors observed lower rates and a more extended period of time for recurrence when the treatment modality consisted of enucleation using Carnoy's solution (11.5\%) or surgical resection (8.4\%) (Al-Moraissi et al., 2017). Complications and morbidity from the treatment with Carnoy's solution have a lower frequency and degree of severity when compared to surgical resection (Alchalabi et al., 2017).

Initially formulated for botanical studies, Carnoy's solution contains $6 \mathrm{ml}$ of absolute alcohol, $3 \mathrm{ml}$ of

${ }^{1}$ Division of Oral and Maxillofacial Surgery, Federal University of Ceará Campus Sobral, Sobral, ${ }^{2}$ Dentist, UNIFOR, ${ }^{3}$ Division of Oral Pathology, ${ }^{4}$ Division of Oral Pathology, ${ }^{5}$ Division of Pharmacology Science, ${ }^{6}$ Department of Morphology, School of Medicine, ${ }^{7}$ Division of Patients with Special Needs, ${ }^{8}$ Division of Oral Radiology, Walter Cantídio University Hospital, Federal University of Ceará, Fortaleza, Brazil. *For Correspondence: samuel.rcarvalho@icloud.com 
chloroform, and $1 \mathrm{ml}$ of glacial acetic acid. The first modification of the solution was the addition of $1 \mathrm{~g}$ of ferric chloride to provide hemostatic characteristics. Used as a complementary therapy to surgery, the Carnoy's solution was applied in patients only in 1933, for the treatment of cysts and cutaneous fistulas. The pioneers in the use of the solution for mandibular lesions were Voorsmit and Stoelinga, in 1981, for treatment of OKTs (Alves et al., 2018). Its use promotes superficial necrosis of the tissue, from a chemical cauterization up to $1.5 \mathrm{~mm}$ deep after 5 minutes of application in bone stores (Blanas et al., 2000; Carvalho et al., 2018; Voorsmit, 1985).

Surgeons associate the Carnoy's solution acts as a corrosive agent shallow penetration that functions as adjuvant conservative therapy in the treatment of odontogenic tumors such as OKT (Al Moraissi et al, 2016; Alchalabi et al, 2017; Alves et al., 2018), amelobastoma (Lee et al., 2012; Alves et al., 2018), while pathologists recognize the solution as a fixative for microscopic analysis (Dias et al., 2016).

The second modification of the solution was due to a 1992 Food and Drug Administration (FDA) ruling, which vetoed the use of chloroform for therapeutic purposes (Carvalho et al., 2018). Thus, the $3 \mathrm{ml}$ of chloroform was replaced by the addition of $3 \mathrm{ml}$ of absolute alcohol, totaling $9 \mathrm{ml}$ in solution. This substitution was done due to the possible damages that this chemical could cause to the health since it is considered possibly carcinogenic (Carvalho et al., 2018). However, results found in some studies, support the relevance of chloroform maintenance in the solution, due to the lower rates of recurrence and better performance of the solution compared to the solution modified by the removal of chloroform (Carvalho et al., 2018).

The application of Carnoy's solution in the tissues does not have standardization. It is applied on the lesion surface before its enucleation (Voorsmit et al., 1981) or on the bone tissue after the enucleation (Carvalho et al., 2018; Leung et al., 2016). Also, it can be injected in the soft tissues adjacent to a lesion or recoating mucosa (Al-Moraissi et al., 2017; Al-Moraissi et al., 2016; Al-Moraissi et al., 2016; Stoelinga, 2005). The use of solution presents a risk of mucosal lesion, gingival edema, nerve damage, among others (Alchalabi et al., 2017). One of the ways to control and ensure homogenous application and release of a topical drug is the use of viscosity polymers. These can be associated with the most variable pharmaceutical formulas, without toxic effect, to form release matrices or even membranes containing the active principle, guaranteeing greater control in its use in the applied place (Pillai and Panchagnula, 2001; Yadav et al., 2017).

We made a modified Carnoy solution with the addition of different viscosity agents, aiming to improve the applicability of the solution to bone surfaces. Through the analysis Raman spectroscopy, we obtained spectral patterns of each substance allowing its specific identification in the middle of a compound, giving us the "fingerprint" of each substrate. Raman spectroscopy promotes the passage of a molecule from its natural state to a vibrational state, in this way, since each molecular specimen has its propper vibration pattern, it is possible to identify each molecule studied (Kann et al., 2015; Kong et al., 2015).

In this context, the aim of the present study was to evaluate the alterations in Carnoy's solution formulations with different viscosity agents and compare them with conventional formulations with and without chloroform.

\section{Materials and Methods}

\section{Obtaining the solutions}

The Carnoy solutions containing chloroform were prepared following the same protocol described by Carvalho et al., (2018). For the preparation of the Carnoy solution without chloroform, $3 \mathrm{~mL}$ of chloroform was replaced by the addition of $3 \mathrm{~mL}$ of absolute alcohol. Viscosity change occurred by insertion of ethyl cellulose $(5 \mathrm{ml})$, glycerol $(5 \mathrm{ml})$, or propylene glycol $(5 \mathrm{ml})$, materials selected for use in oral cavity gels. Thus, there were eight solutions to be analyzed.

\section{Pharmacological characterization (density, $p H$, viscosity,} $\mathrm{Fe}^{3+}$ concentration)

Pharmacological characterization of the solutions was performed by determining the mass density and relative density using a clean and dry pycnometer (Prolab Picnometer Materials of laboratory, São Paulo - SP), with a capacity of $12.7 \mathrm{ml}$ previously calibrated and Ostwald viscometer (Viscotester 6L Viscometer Thermo Haake - Thermo Fisher Scientif Inc, Germany). A pH meter was used to determine the $\mathrm{pH}$ (bench $\mathrm{pH}$ meter model DM 23 - Digimed, Campo Grande Brazil). The concentration of $\mathrm{Fe}^{3+}$ was determined using ultraviolet / visible (UV / visible) spectroscopy (GENESYS 20 UV/ VIS Spectrophotometer, Thermo Fisher Scientific Inc., Germany), by reacting potassium thiocyanate in aqueous solution (Tang et al., 2016).

\section{Raman spectroscopy}

The spatial distribution of the inorganic components was determined by the relative intensities corresponding to the peaks of Raman micro spectrometry (Xplora, Horiba Scientific, Paris, France). For this purpose, an argon laser with a wavelength of $638 \mathrm{~nm}$ and a power of $3.2 \mathrm{~mW}$ (Olympus American Inc) was used. In addition, the analyses were performed at a $10 x$ magnification where the focus was performed on the surface of the solution that was in a glass cuvette. The Raman spectra were obtained in the range of $200 \mathrm{~cm}^{-1}$ to $3,500 \mathrm{~cm}^{-1}$ with three accumulations of 10 seconds.

All the readings were performed at the same temperature and pressure $\left(22^{\circ} \mathrm{C}\right.$ and $\left.1 \mathrm{~atm}\right)$, using $10 \mathrm{ml}$ for analysis (Carvalho et al., 2018). Before data acquisition, the apparatus was calibrated with silica with a wavelength of $520 \mathrm{~cm}^{-1}$, as recommended by the manufacturer. Subsequently, all spectra were analyzed and manipulated using OriginPro 9.0 software (OriginLab Corporation, Northampton, Massachusetts, USA). All data were processed with baseline correction, smoothing by the polynomial method (Savitzk-Golay), and the peaks were identified as to their position and intensity through 
the Gaussian and Lorentzian method to determine the characterization and deconvolution of the graphs (Nouri et al., 2015).

\section{Data analysis}

All statistical analysis was performed using software Bioestat 5.3. Statistical analysis of the different viscosity agents and concentration of $\left[\mathrm{Fe}^{3+}\right]$ in Carnoy's solution without chloroform were performed by unpaired Student's t-test. The significance level of 5\% was adopted, and the analyses were performed through the software Bioestat 5.3 .

\section{Results}

\section{Pharmacological Characterization}

Carnoy's solutions with and without chloroform, when mixed with ethyl cellulose $(5 \mathrm{ml})$, showed precipitation of material at the bottom of the flask and presence of undiluted thickening agent in solution. Thus, this study group was removed.

The relative density and viscosity of Carnoy's solution were influenced by the presence of chloroform and viscosity agents. When present, viscosity agents render chloroform-free solutions more viscous, unlike that found in Carnoy's solutions without viscosity agents. Despite this characteristic, the viscosity was increased in all groups.

The $\mathrm{pH}$ of all solutions is highly acidic, and these are influenced by the presence of chloroform. The presence of the viscosity agent appears to reduce the difference in $\mathrm{pH}$ increase when compared to Carnoy's solution with and without chloroform plus different viscosity agents. The $\mathrm{pH}$ had higher acidity when glycerol was used in comparison to propylene glycol, despite the decrease in viscosity (Table 1).

The concentration of $\mathrm{Fe}^{3+}$ ions analyzed by UV/Visible spectroscopy showed a slight increase in solutions without chloroform when the viscosity agents were used. While in the presence of chloroform it presented lower values (Tables 2 and 3).

\section{Raman spectroscopy}

The spectra of the viscosity agents (Figure 1) were obtained and described for the relative intensity of

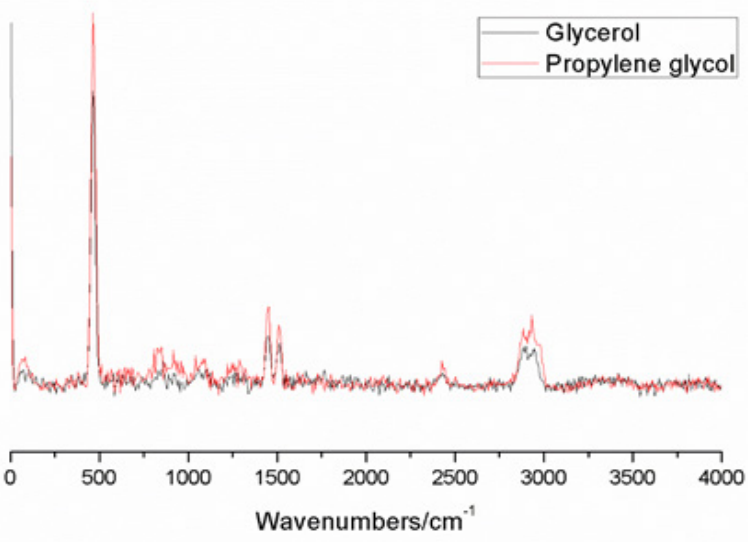

Figure 1. Spectra of Glycerol and Propylene Glycol with a Red Laser (638nm) Compiled in OriginPro 9.0 Software ${ }^{\circledR}$.

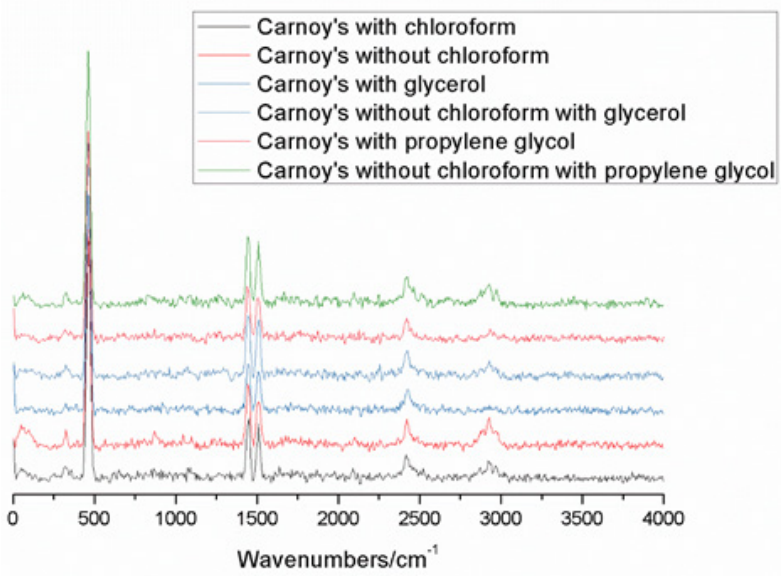

Figure 2. Carnoy's Solution with and without Chloroform and Viscosity agents Evidencing the most Significant Variation between 2,500 $\mathrm{cm}^{-1}$ and $3,500 \mathrm{~cm}^{-1}$, with Red Laser (638 nm) Compiled in OriginPro 9.0 Software ${ }^{\circledR}$.

the peaks in relation to the highest peak of the substance, determining from there the peaks in very weak, weak, medium, strong, very strong and shoulders (Table 4).

The spectra of the Carnoy solutions were superimposed on graphs that were quite similar. The region between $2,500 \mathrm{~cm}^{-1}$ and $3,500 \mathrm{~cm}^{-1}$ was the one with the greatest variation since the variations between the peaks in the

Table 1. Pharmacological Characterization of Carnoy's Solution with and without Chloroform Associated with Differents Viscosity agents in Relation to Water

\begin{tabular}{lcccc}
\hline & $\begin{array}{c}\text { Mean spreading time } \\
(\mathrm{s})\end{array}$ & $\begin{array}{c}\text { Density }(\mathrm{g} / \mathrm{ml}) \\
\text { Viscosity }\left(\mathrm{mPa}{ }^{\star} \mathrm{s}\right)\end{array}$ & $\mathrm{pH}$ \\
\hline Water & 7.24 & 0.99704 & 1 & 7.0 \\
Carnoy's solution with chloroform & 7.36 & 10.805 & $1.1017^{\mathrm{A}}$ & $0.12^{\mathrm{a}}$ \\
Carnoy's solution with chloroform + glycerol & 7.66 & 11.049 & $1.1725^{\mathrm{A}}$ & $0.04^{\mathrm{a}}$ \\
Carnoy's solution with chloroform + propylene glycol & 7.94 & 11.289 & $1.2417^{\mathrm{A}}$ & $0.22^{\mathrm{a}}$ \\
Carnoy's solution without chloroform & 7.72 & 0.8862 & $0.9478^{\mathrm{B}}$ & $0.56^{\mathrm{b} . \mathrm{c}}$ \\
Carnoy's solution without chloroform + glycerol & 10.48 & 0.9861 & $1.4309^{\mathrm{C}}$ & $0.09^{\mathrm{d}}$ \\
Carnoy's solution without chloroform + propylene glycol & 16.8 & 10.758 & $2.5037^{\mathrm{D}}$ & $0.24^{\mathrm{d}}$ \\
\hline
\end{tabular}

Capital letters show statistical analysis for viscosity values, lowercase letters for $\mathrm{pH}$ values. Different letters correspond to the presence of statistical difference, while equal letters correspond to absence of statistical difference. A, p, $0.3023 ; \mathrm{B}, \mathrm{C}, \mathrm{D}, \mathrm{p}<0.0001 ; \mathrm{a}, \mathrm{p}, 0.1677 ; \mathrm{b}, \mathrm{c}, \mathrm{d}, \mathrm{p}, 0.0032$. 
Table 2. The Concentration of $\left[\mathrm{Fe}^{3+}\right]$ in Carnoy's Solution with Chloroform by UV/Vis Calculated by the Line equation in the Calibration Curve $(\mathrm{Abs}=0.1521$. $\left.\left[\mathrm{Fe}^{3+}\right]+0.0077\right)$.

\begin{tabular}{lc}
\hline Solution & {$\left[\mathrm{Fe}^{3+}\right](\mu \mathrm{g} / \mathrm{ml})$} \\
\hline Carnoy's solution & 8.16 \\
Carnoy's solution + Glycerol & 8.37 \\
Carnoy's solution + Propylene glycol & 8.33 \\
\hline
\end{tabular}

Table 3. The Concentration of $\left[\mathrm{Fe}^{3+}\right]$ in Carnoy's Solution without Chloroform by UV/Vis Calculated by the Line Equation in the Calibration Curve $(\mathrm{Abs}=0.1521$. $\left.\left[\mathrm{Fe}^{3+}\right]+0.0077\right)$.

\begin{tabular}{lc}
\hline Solution & $\begin{array}{c}{\left[\mathrm{Fe}^{3+}\right]} \\
(\mu \mathrm{g} / \mathrm{ml})\end{array}$ \\
\hline Carnoy's solution without chloroform & $8.72^{\mathrm{a}}$ \\
Carnoy's solution without chloroform + Glycerol & $9.95^{\mathrm{b}}$ \\
Carnoy's solution without chloroform + Propylene glycol & $8.93^{\mathrm{a}}$ \\
\hline
\end{tabular}

Different letters correspond to the presence of statistical difference $(\mathrm{p}<0.0001)$.

other regions of the analyzed spectrum were small (Figure 2).

\section{Discussion}

Ethyl cellulose did not prove to be a usable viscosity agent since the formulated solutions changed by precipitate formation and suspension of the thickening agent. The increase in viscosity was observed with the use of thickening agents. Propylene glycol showed a more significant increase over glycerol. Both agents had higher viscosity increase when associated with Carnoy's solution without chloroform. This fact may ensure better clinical application of solutions with increased viscosity, whereas controlling the area of application of adjuvant therapy ensures a greater reduction of complications associated with the use of Carnoy's solution (Ribeiro Júnior et al., 2012).

The $\mathrm{pH}$ of the solutions showed an acid pattern, the glycerol formulation being the one with the lowest values. These values can be explained by the presence of acetic acid, chloroform and ferric chloride in solution (Carvalho et al., 2018). Carnoy's solution with chloroform was more clinically effective when compared to chloroform-free solution because the recurrence rates in OKT were lower in the first group (Dashow et al., 2015). Chloroform appears to be associated with a reduction in the $\mathrm{pH}$ of the solution and with the capacity of recurrence of the injuries (Carvalho et al., 2018). Thus, the authors believe that the use of glycerol and propylene glycol may show improvement in clinical outcomes when used since the $\mathrm{pH}$ is diminished in its use.

The concentration of $\mathrm{Fe}^{3+}$ appears to increase with the use of viscosity agents, being higher in the glycerol group than the propylene glycol group. It was noteworthy that the solutions that did not present chloroform in their composition obtained higher concentrations in relation to the solutions that presented chloroform.

Ferric chloride was characterized as a hemostatic
Table 4. Characteristic Peaks of Viscosity Agents

\begin{tabular}{lccc}
\hline Glycerol & & \multicolumn{2}{c}{ Propylene glycol } \\
\hline Peak & Intensity & Peak & Intensity \\
464 & m & 465 & s \\
837 & W & $\underline{518}$ & $\underline{\text { vw }}$ \\
914 & vw & 837 & s \\
$\underline{1052}$ & $\underline{\text { w }}$ & 914 & $\mathrm{~m}$ \\
1250 & vw & $\underline{1078}$ & $\underline{\mathrm{m}}$ \\
1454 & w & 1238 & vw \\
2888 & S & $\underline{1280}$ & $\underline{\text { vw }}$ \\
2941 & s & 1449 & s \\
& & $\underline{1502}$ & $\underline{\text { vw }}$ \\
& & 2878 & vs \\
& & 2932 & vs \\
& & $\underline{2972}$ & $\underline{\text { vs }}$ \\
\hline
\end{tabular}

vw, very weak; w, weak; $\mathrm{m}$, medium; s, strong; vs, very strong Underlined items can differentiate substances.

agent that acts by coagulative necrosis, (Nouri et al., 2015), which from the therapeutic point of view may be associated with lower rates of relapse in odontogenic neoplasms (Carvalho et al., 2018). Thus, the use of viscosity agents may favor this characteristic since we observed an increase in $\mathrm{Fe}^{3+}$ ion concentration, mainly in glycerol.

The spectra of Carnoy's solution can be differentiated for the presence or absence of chloroform, mainly in the region of $200 \mathrm{~cm}^{-1}$ at $1,600 \mathrm{~cm}^{-1}$. However, the use of viscosity agents did not allow the differentiation of peaks in the area. The main difference in the present study was observed in the region between $2,500 \mathrm{~cm}^{-1}$ and 3,500 $\mathrm{cm}^{-1}$, characterized mainly by the phenol and alcohol groups. These groups were present in all solutions since the solvent of the solutions was the alcohol, and the viscosity agents have such groups in their composition. Glycerol $\left(\mathrm{C}_{3} \mathrm{H}_{8} \mathrm{O}_{3}\right)$ differs from propylene glycol $\left(\mathrm{C}_{3} \mathrm{H}_{8} \mathrm{O}_{2}\right)$ by the presence of an oxygen molecule that has the most reason to justify the similarity of the Raman spectra of these substances. Therefore, obtaining a fingerprint for the solutions of the present study becomes challenging, since the peaks that are unique for a particular substance have low intensity.

In conclusions, Glycerol and propylene glycol were shown as possible viscosity agents for use with Carnoy's solution with and without chloroform. Propylene glycol is associated with higher viscosity, and glycerol is associated with acidic $\mathrm{pH}$ and higher concentrations of $\mathrm{Fe}^{3+}$ ions in solution. The characterization of Carnoy's solution with these viscosity agents can be hampered by the chemical similarity of the compounds and the alcohol component of the solutions.

\section{Acknowledgements}

The authors would like to thank Conselho Nacional Desenvolvimento Científico e Tecnológico (CNPq)/Brazil. 


\section{Ethical approval}

This article does not contain any studies with human participants or animals performed by any of the authors. Informed consent

For this type of study, formal consent is not required.

\section{Funding}

This work was supported by grants from Conselho Nacional Desenvolvimento Científico e Tecnológico $(\mathrm{CNPq}) /$ Brazil.

\section{Conflict of interest}

The authors declare that they have no conflict of interest.

\section{References}

Al-Moraissi EA, Dahan AA, Alwadeai MS, et al (2017). What surgical treatment has the lowest recurrence rate following the management of keratocystic odontogenic tumor?: A large systematic review and meta-analysis. $J$ Craniomaxillofac Surg, 45, 131-44.

Al-Moraissi EA, Pogrel MA, Ellis E (2016). Does the excision of overlying oral mucosa reduce the recurrence rate in the treatment of the Keratocystic Odontogenic tumor? A systematic review and meta-analysis. J Oral Maxillofac Surg, 74, 1974-82.

Al-Moraissi EA, Pogrel MA, Ellis E (2016). Enucleation with or without adjuvant therapy versus marsupialization with or without secondary enucleation in the treatment of keratocystic odontogenic tumors: A systematic review and meta-analysis. J Craniomaxillofac Surg, 44, 1395-403.

Alchalabi NJ, Merza AM, Issa SA (2017). Using carnoy's solution in treatment of Keratocystic Odontogenic tumor. Ann Maxillofac Surg, 7, 51-6.

Alves DBM, Tuji FM, Alves FA, et al (2018). Evaluation of mandibular odontogenic keratocyst and ameloblastoma by panoramic radiograph and computed tomography. Dentomaxillofac Radiol, 47, 20170288.

Blanas N, Freund B, Schwartz M, et al (2000). Systematic review of the treatment and prognosis of the odontogenic keratocyst. Oral Surg Oral Med Oral Pathol Oral Radiol Endod, 90, 553-8.

Carvalho FSR, Feitosa VP, Silva PGB, et al (2018). Evaluation of different therapeutic Carnoy's formulations on hard human tissues: A Raman microspectroscopy, microhardness, and scanning electron microscopy study. $J$ Craniomaxillofac Surg, 46, 749-58.

Cavalcante RB, Turatti E, Daniel AP, et al (2016). Retrospective review of oral and maxillofacial pathology in a Brazilian paediatric population. Eur Arch Paediatr Dent, 17, 115-22.

Cutler EC, Zollinger R (1933). The use of sclerosing solutions in the treatment of cysts and fistulae. Am J Surg, 19, 411-8.

da Silva LP, Gonzaga AK, Severo ML, et al (2018). Epidemiologic study of odontogenic and non-odontogenic cysts in children and adolescents of a Brazilian population. Med Oral Patol Oral Cir Bucal, 23, e49-53.

Dashow JE, McHugh JB, Braun TM, et al (2015). Significantly decreased recurrence rates in Keratocystic Odontogenic tumor with simple enucleation and curettage using carnoy's versus modified carnoy's solution. J Oral Maxillofac Surg, 73, 2132-5.

Dias AR, Pereira MA, Mello ES, et al (2016). Carnoy's solution increases the number of examined lymph nodes following gastrectomy for adenocarcinoma: a randomized trial. Gastric Cancer, 19, 136-42.
Gurol M, Uckan S, Guler N, Yatmaz PI (2001). Surgical and reconstructive treatment of a large ossifying fibroma of the mandible in a retrognathic patient. J Oral Maxillofac Surg, 59, 1097-1100.

Kann B, Offerhaus HL, Windbergs M, et al. (2015). Raman microscopy for cellular investigations--From single cell imaging to drug carrier uptake visualization. Adv Drug Deliv Rev, 89, 71-90.

Kong K, Kendall C, Stone N, et al (2015). Raman spectroscopy for medical diagnostics--From in-vitro biofluid assays to in-vivo cancer detection. Adv Drug Deliv Rev, 89, 121-34.

Lee PK, Samman N, Ng IO (2012). Unicystic ameloblastoma - use of Carnoy`s solution after enucleation. Int J Oral Maxillofac Surg, 33, 263-7.

Leung YY, Lau SL, Tsoi KY, et al (2016). Results of the treatment of keratocystic odontogenic tumours using enucleation and treatment of the residual bony defect with Carnoy's solution. Int J Oral Maxillofac Surg, 45, 1154-8.

Nouri S, Sharif MR, Sahba S (2015). The effect of ferric chloride on superficial bleeding. Trauma Mon, 20, e18042.

Pillai O, Panchagnula R (2001). Polymers in drug delivery. Curr Opin Chem Biol, 5, 447-51.

Qin X, Li J, Chen X, Long X (2005). The glandular odontogenic cyst. Clinicopathologic features and treatment of 14 cases. J Oral Maxillofac Surg, 63, 694-9.

Ribeiro Junior O, Borba AM, Alves CA, et al (2012). Keratocystic odontogenic tumors and Carnoy's solution: results and complications assessment. Oral Dis, 18, 548-57.

Stoelinga PJ (2001). Long-term follow-up on keratocysts treated according to a defined protocol. Int J Oral Maxillofac Surg, 30, 14-25.

Stoelinga PJ (2005). The treatment of odontogenic keratocysts by excision of the overlying, attached mucosa, enucleation, and treatment of the bony defect with carnoy solution. J Oral Maxillofac Surg, 63, 1662-6.

Stoelinga PJ, Bronkhorst FB (1988). The incidence, multiple presentation and recurrence of aggressive cysts of the jaws. J Craniomaxillofac Surg, 16, 184-95.

Tang S, Chang Y, Shen W, et al (2016). Selective extraction by dissolvable (nitriloacetic acid-nickel)-layered double hydroxide coupled with reaction with potassium thiocyanate for sensitive detection of iron(III). Talanta, 154, 416-22.

Voorsmit RA (1985). The incredible keratocyst: a new approach to treatment. Dtsch Zahnarztl Z, 40, 641-4.

Voorsmit RA, Stoelinga PJ, van Haelst UJ (1981). The management of keratocysts. J Maxillofac Surg, 9, 228-36.

Yadav NK, Nanda S, Sharma G, et al (2017). Systematically optimized Ketoprofen-Loaded novel proniosomal formulation for periodontitis: In vitro characterization and in vivo pharmacodynamic evaluation. AAPS Pharm SciTech, 18, 1863-80.

\section{(ब) $\odot$}

This work is licensed under a Creative Commons AttributionNon Commercial 4.0 International License. 